
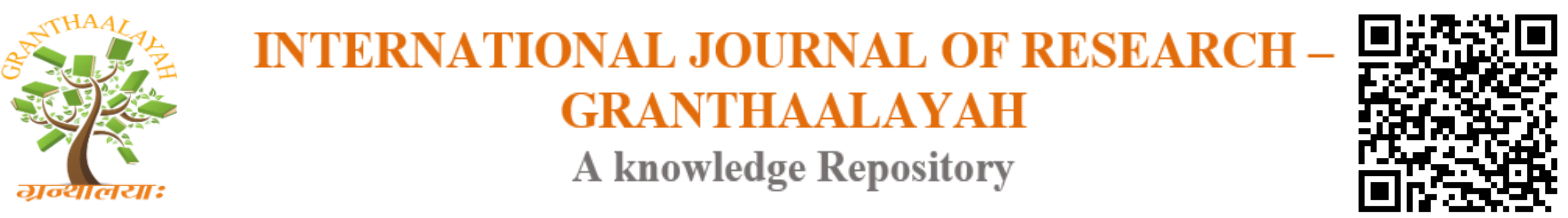

Science

\title{
EXPERIMENTAL STUDY OF FLAT PLATE SOLAR COLLECTORS WITH VARIOUS FLOW RATE OF WATER
}

\author{
Anupras Shukla ${ }^{1}$, Prof. Pushpraj Singh ${ }^{2}$ \\ ${ }^{1}$ M.Tech, Student, (Thermal Engineering) Department of Mechanical Engineering, \\ Rewa Institute of Technology, Rewa (M.P.), India \\ 2 Assistant professor, Department of Mechanical Engineering, Rewa Institute of Technology, \\ Rewa (M.P.), India
}

\begin{abstract}
In this paper, we are studying about solar water heater. The solar water heater are consisting of several components such as circular pipe, flexible pipe, and metallic container for water and circulating pump. We are analyzed the outlet temperatures of hot water using of various flow rate (in liters/ Minutes).

Keywords: Solar Collector; Flexible Pipe; Circulating Pump.

Cite This Article: Anupras Shukla, and Prof. Pushpraj Singh. (2017). "EXPERIMENTAL STUDY OF FLAT PLATE SOLAR COLLECTORS WITH VARIOUS FLOW RATE OF WATER." International Journal of Research - Granthaalayah, 5(10), 112-116. https://doi.org/10.29121/granthaalayah.v5.i10.2017.2288.
\end{abstract}

\section{Introduction}

We are using the circulating the pump for purpose of the circulating the water in pipe, water is circulated in the pipe and some pipe are attached with solar collector. The solar collector is achieving the radiation from sun energy and heat energy transferred into water, which are flow in pipe. We are using the regulator for the purpose of the regulate the flow rate of water.

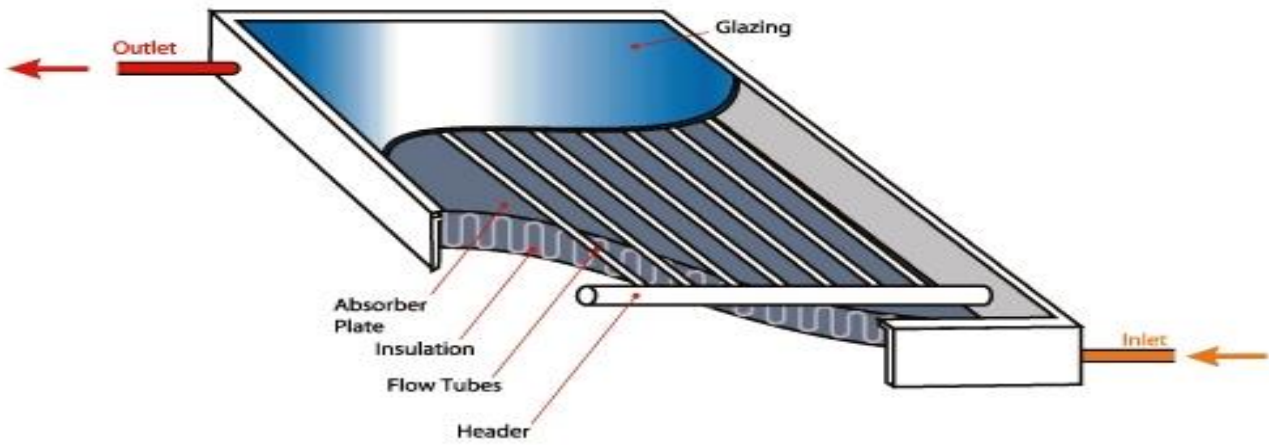

Figure 1: Solar Water Heater 


\section{Experimental Setup}

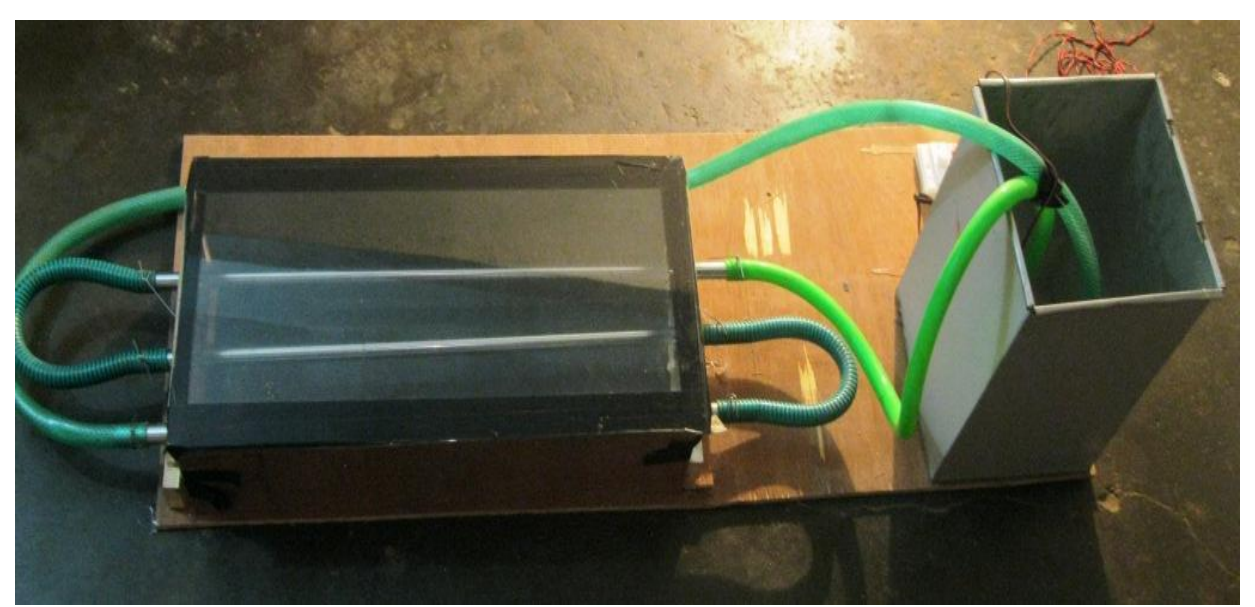

Figure 2: Experimental setup

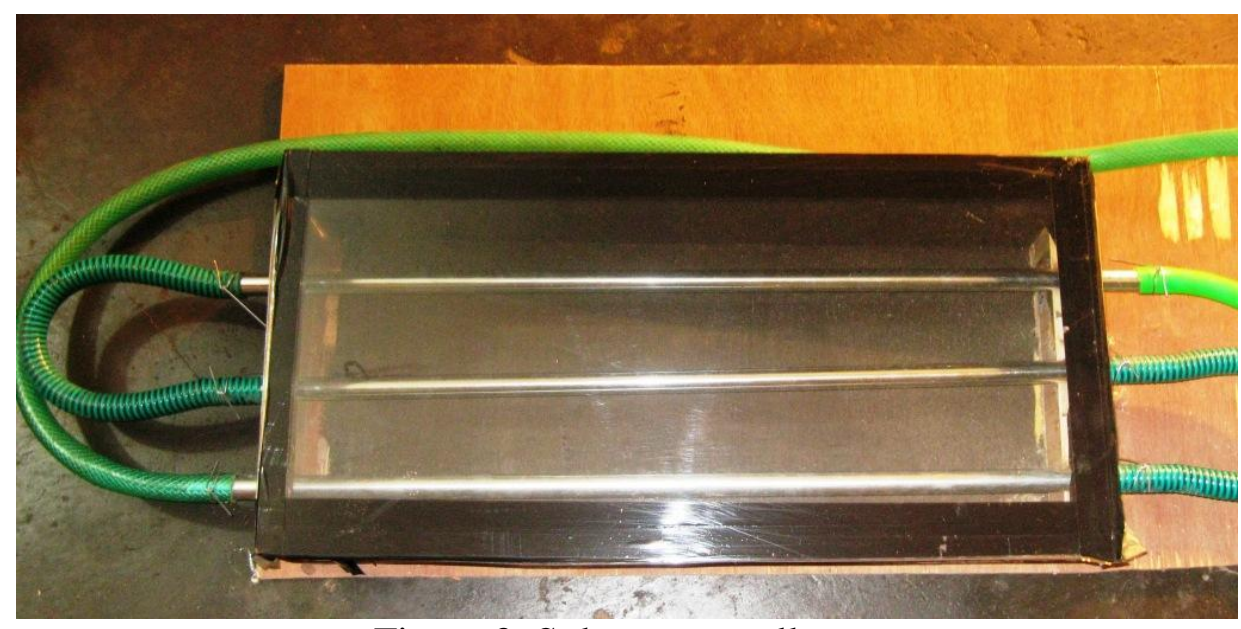

Figure 3: Solar water collector

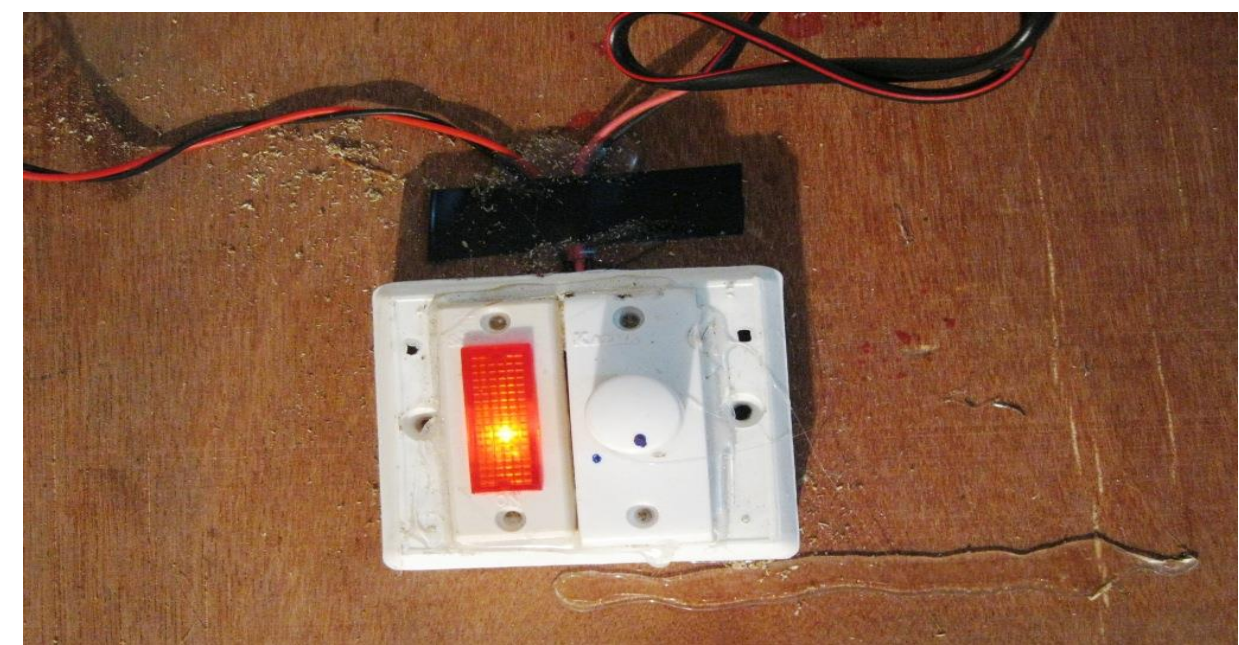

Figure 4: Control panel 


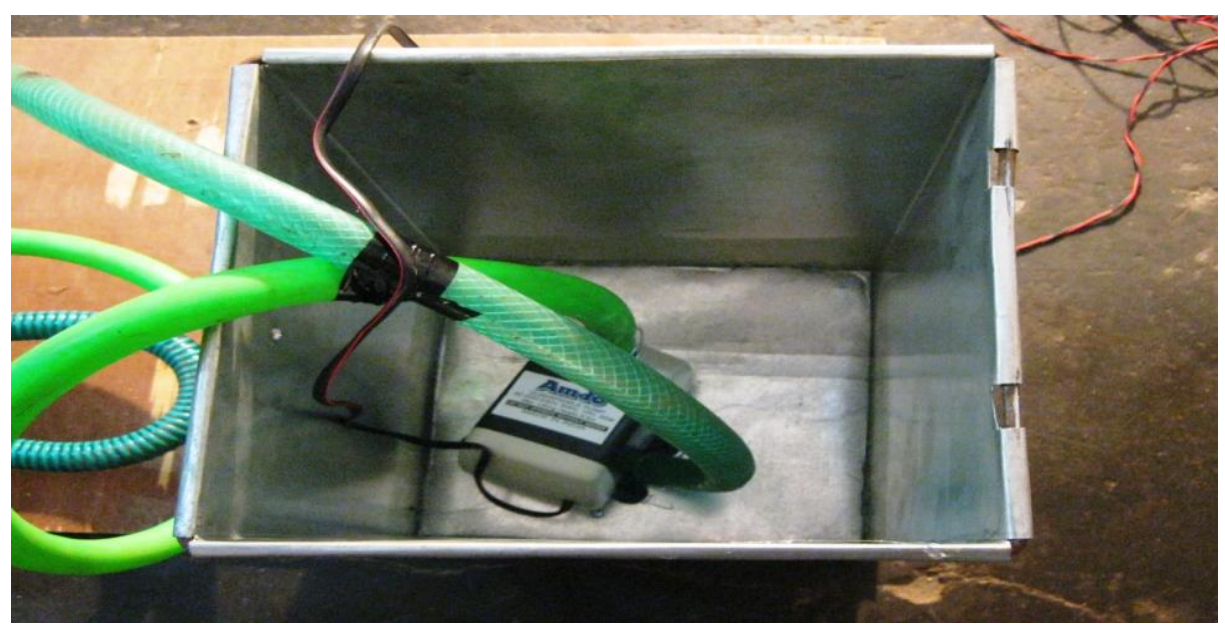

Figure 5: container with water circulating Pump

\section{Results and Discussion}

Table 1: Time and temperature with water flow rate 10 liters/ Minutes

\begin{tabular}{|c|c|c|}
\hline Sr. No. & Time & Temperature in ${ }^{\circ} \mathbf{C}$ \\
\hline 1 & $10: 00$ & 30 \\
\hline 2 & $11: 00$ & 34 \\
\hline 3 & $12: 00$ & 38 \\
\hline 4 & $13: 00$ & 45 \\
\hline 5 & $14: 00$ & 43 \\
\hline 6 & $15: 00$ & 39 \\
\hline 7 & $16: 00$ & 37 \\
\hline 8 & $17: 00$ & 34 \\
\hline
\end{tabular}

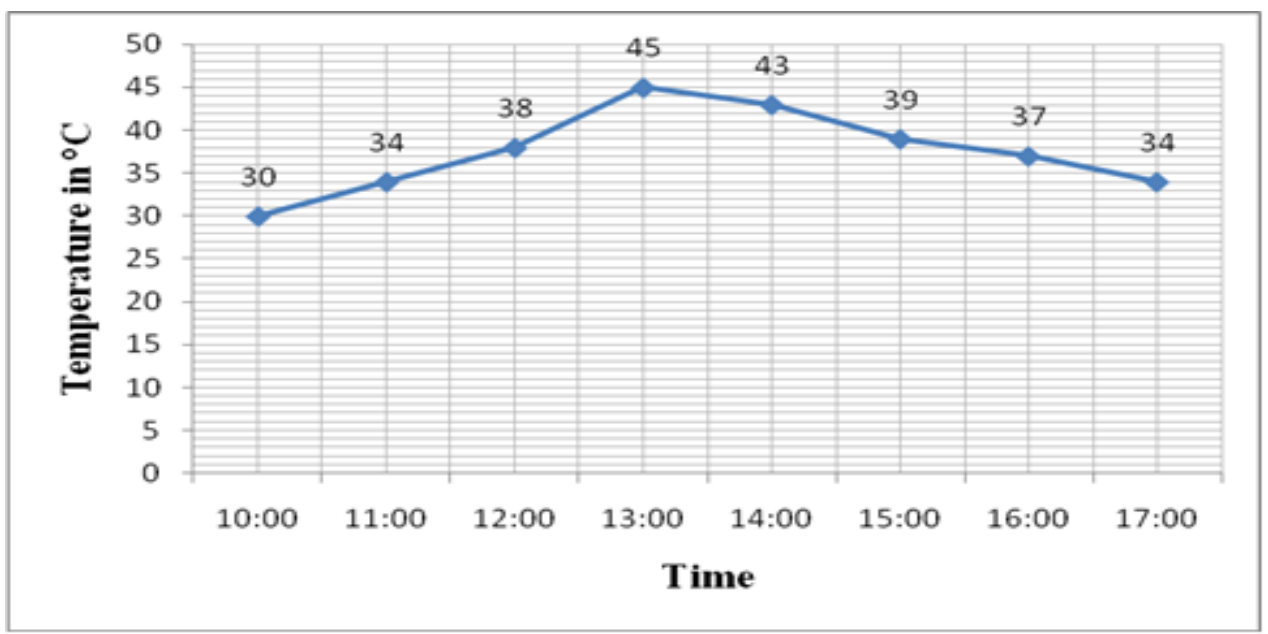

Figure 6: Time and temperature with water flow rate 10 liters/ Minutes 
Table 2: Time and temperature with water flow rate 12 liters/ Minutes

\begin{tabular}{|c|c|c|}
\hline Sr. No. & Time & Temperature in ${ }^{\circ} \mathbf{C}$ \\
\hline 1 & $10: 00$ & 32 \\
\hline 2 & $11: 00$ & 36 \\
\hline 3 & $12: 00$ & 40 \\
\hline 4 & $13: 00$ & 52 \\
\hline 5 & $14: 00$ & 46 \\
\hline 6 & $15: 00$ & 44 \\
\hline 7 & $16: 00$ & 39 \\
\hline 8 & $17: 00$ & 36 \\
\hline
\end{tabular}

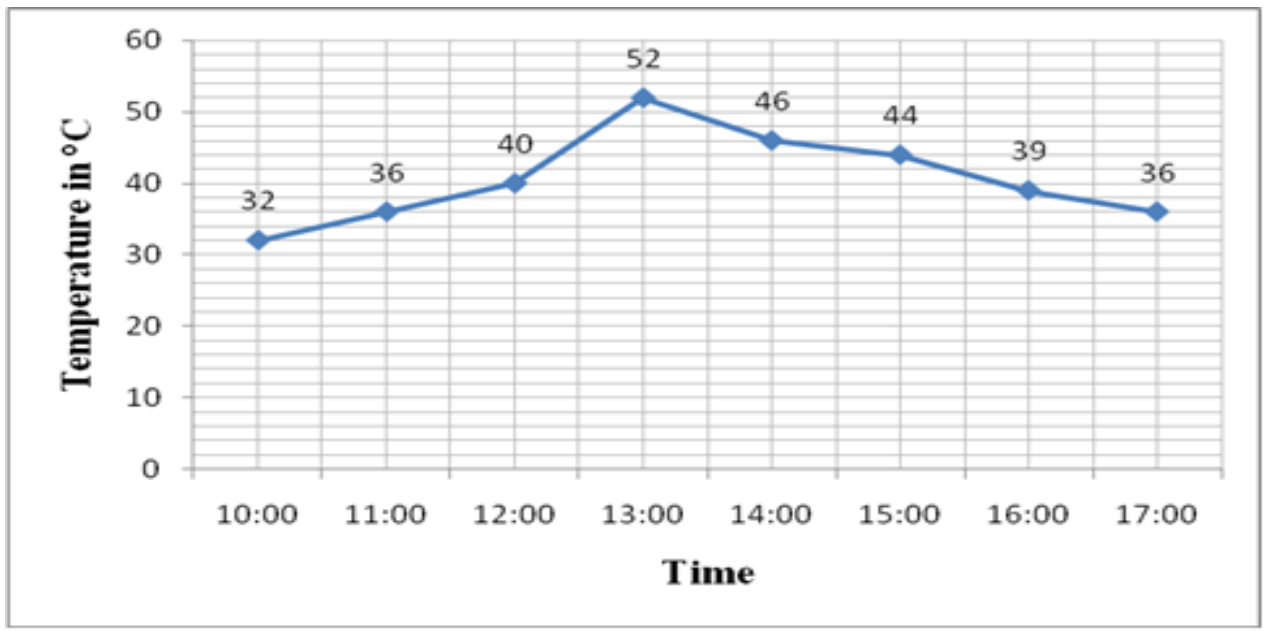

Figure 7: Time and temperature with water flow rate 12 liters/ Minutes

Table 3: Time and temperature with water flow rate 14 liters/ Minutes

\begin{tabular}{|c|c|c|}
\hline Sr. No. & Time & Temperature in ${ }^{\circ} \mathbf{C}$ \\
\hline 1 & $10: 00$ & 33 \\
\hline 2 & $11: 00$ & 39 \\
\hline 3 & $12: 00$ & 44 \\
\hline 4 & $13: 00$ & 49 \\
\hline 5 & $14: 00$ & 44 \\
\hline 6 & $15: 00$ & 41 \\
\hline 7 & $16: 00$ & 39 \\
\hline 8 & $17: 00$ & 34 \\
\hline
\end{tabular}




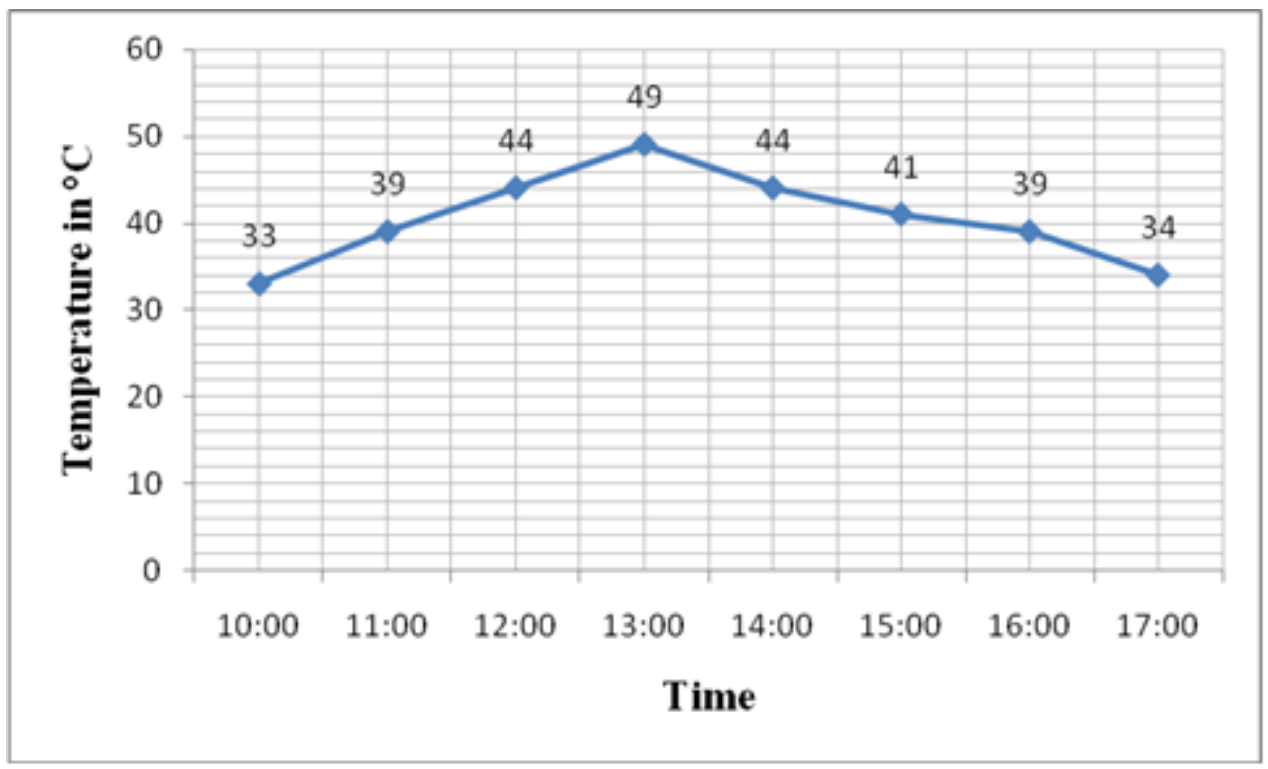

Figure 8: Time and temperature with water flow rate 14 liters/ Minutes

\section{Conclusion}

In this experimental study, we are analyzed the maximum temperature of hot water using of various flow rate of water, which are controlled with the help of regulator. We are finding out the maximum temperature $52{ }^{\circ} \mathrm{C}$ at the Time 13:00 using of water flow rat are 12 liters/ Minutes, which are shown in Table 2 .

\section{References}

[1] Azad E. Heat Mass Transfer, 2009, 45(5): 645-649.

[2] Hussein H M S, El-Ghetany H H, Nada S Energy Conversion and Management, 2006, 47(11/12): 1539-1549.

[3] Hussein H M S. Energy Conversion and Management, 2007, 48(4): 1266-1272.

[4] Zhao Yaohua, Heat transfer characteristics of flat micro heat pipe array, CIESC Journal, 2011, 62(2): 336-343.

[5] Zhao Yaohua. Numerical investigation on heat transfer of vertical micro-heat pipe arrays. CIESC Journal, 2014, 65(2): 508- 515. 